\title{
Fatigue Strength and Crack Initiation Mechanism of Very-High-Cycle Fatigue for Low Alloy Steels
}

\author{
YOUSHI HONG, AIGUO ZHAO, GUIAN QIAN, and CHENGEN ZHOU
}

The fatigue strength and crack initiation mechanisms of very-high-cycle fatigue (VHCF) for two low alloy steels were investigated. Rotary bending tests at $52.5 \mathrm{~Hz}$ with hour-glass type specimens were carried out to obtain the fatigue propensity of the test steels, for which the failure occurred up to the VHCF regime of $10^{8}$ cycles with the S-N curves of stepwise tendency. Fractography observations show that the crack initiation of VHCF is at subsurface inclusion with "fish-eye" pattern. The fish-eye is of equiaxed shape and tends to tangent the specimen surface. The size of the fish-eye becomes large with the increasing depth of related inclusion from the surface. The fish-eye crack grows faster outward to the specimen surface than inward. The values of the stress intensity factor $\left(K_{I}\right)$ at different regions of fracture surface were calculated, indicating that the $K_{I}$ value of fish-eye crack is close to the value of relevant fatigue threshold $\left(\Delta K_{t h}\right)$. A new parameter was proposed to interpret the competition mechanism of fatigue crack initiation at the specimen surface or at the subsurface. The simulation results indicate that large inclusion size, small grain size, and high strength of material will promote fatigue crack initiation at the specimen subsurface, which are in agreement with experimental observations.

DOI: $10.1007 / \mathrm{s} 11661-011-0816-7$

(C) The Minerals, Metals \& Materials Society and ASM International 2011

\section{INTRODUCTION}

THE research of metal fatigue dates back more than 150 years. ${ }^{[1]}$ Conventionally, the fatigue limit of metallic materials is recognized as the fatigue strength at the loading cycles of $10^{7}$ without failure. ${ }^{[2]}$ Although Kikukawa et al. ${ }^{[3]}$ presented fatigue data at failure cycles beyond $10^{8}$ in the mid-1960s, which were tested with loading frequencies from 13 to $100 \mathrm{kHz}$, their attention was directed toward the frequency effect on the fatigue strength of mild steels. In the mid-1980s, Naito et al. ${ }^{[4,5]}$ clearly reported the occurrence of fatigue fracture at the cycles beyond $10^{8}$ with specific fatigue characteristics for carburized steels. Since then, a new regime of fatigue research, namely, very-high-cycle fatigue $(\mathrm{VHCF}),{ }^{[6]}$ also called ultra-high-cycle fatigue, ${ }^{[7]}$ ultra-long-life fatigue, ${ }^{[8]}$ or gigacycle fatigue, ${ }^{[9]}$ which concentrated on the specific fatigue behavior at failure cycles beyond $10^{7}$ and even up to $10^{11}$ loading cycles, has attracted investigators in this field. The importance

YOUSHI HONG, Professor, and AIGUO ZHAO, Doctoral Student, are with the State Key Laboratory of Nonlinear Mechanics, Institute of Mechanics, Chinese Academy of Sciences, Beijing 100190, P.R. China. Contact email: hongys@imech.ac.cn GUIAN QIAN, formerly Doctoral Student with the State Key Laboratory of Nonlinear Mechanics, Institute of Mechanics, Chinese Academy of Sciences, is now Postdoctoral Fellow with the PSI-Paul Scherrer Institute, Laboratory for Nuclear Materials, CH-5232 Villigen, Switzerland. CHENGEN ZHOU, formerly Doctoral Student with the State Key Laboratory of Nonlinear Mechanics, Institute of Mechanics, Chinese Academy of Sciences, is now Associate Professor with the College of Science, Inner Mongolia University of Technology, Huhhot 010051, P.R. China.

Manuscript submitted March 27, 2011.

Article published online September 15, 2011 of $\mathrm{VHCF}$ research is no doubt related to the growing trend of engineering applications, including aircraft, automobile, ship, railway, bridge, etc., for which the components and structures are required to endure the fatigue life larger than $10^{7}$ loading cycles, and even requiring $10^{11}$ life cycles of endurance in some vital cases.

Since the mid-1980s, the results of fatigue failure beyond $10^{7}$ loading cycles were successively published, e.g., References 10 through 20. The characteristics of crack initiation and its early growth are essential aspects in the understanding of the VHCF mechanism. For the case of low-cycle and high-cycle fatigue, cracks originate from the specimen surface due to localized plastic deformation with persistent slip process. For the case of VHCF, on the contrary, cracks seem prone to initiate at the specimen subsurface (interior). It is natural to ask in which situation will cracks initiate at the surface, and in which other situation will cracks originate at the subsurface. For this, the competition mechanism of different crack initiation modes is not clear. Although the observations of "fish-eye" and "optical dark-area" patterns were confirmed in the literature, ${ }^{[8,11,18]}$ there is still a lack of knowledge in the interpretation of the influence tendency on the crack initiation process.

In this article, the fatigue strength and the crack initiation mechanism of VHCF are investigated with two low alloy steels. The hour-glass type specimens were tested by using a rotary bending machine operating at a frequency of $52.5 \mathrm{~Hz}$. The results show that VHCF damage and failure occurred for both test steels with the $\mathrm{S}-\mathrm{N}$ curves of stepwise tendency. The fractography of broken specimens was examined to reveal that fatigue cracks almost initiate at the specimen subsurface for 
VHCF with a fish-eye pattern. The stress intensity factors at different zones of fracture surface are calculated to evaluate the cracking propensity. A new parameter is proposed to interpret the competition mechanism of fatigue crack initiation from the specimen surface or at the subsurface, which is affected by inclusion size, grain size, strength of material, and applied stress.

\section{FATIGUE TESTING AND RESULTS}

The test materials in the present investigation are two low alloy steels, i.e., the Chinese brands of GCr15 (equivalent US code SAE 52100 or Japan code SUJ2) and $40 \mathrm{Cr}$ (equivalent US code AISI 5140 or Japan code $\mathrm{SCr} 440$ ). GCr15, designated as material $\mathrm{G}$ in the following text, is a bearing steel with main chemical compositions of 1.0 pet $\mathrm{C}$ and 1.5 pct $\mathrm{Cr}$ ( $\mathrm{Fe}$ balance). $40 \mathrm{Cr}$, designated as material $\mathrm{C}$ in the following text, is a structural steel with main chemical composition of 0.4 pet $\mathrm{C}$ and 1.0 pet $\mathrm{Cr}$ (Fe balance). Hour-glass shape specimens were machined with the minimum diameter of $3 \mathrm{~mm}$ and the round notch radius of $7 \mathrm{~mm}$, as shown in Figure 1. The stress concentration factor for the specimen is simply calculated as 1.06 .

The raw specimens of material $G$ were heated at $1118 \mathrm{~K}\left(845^{\circ} \mathrm{C}\right)$ for 2 hours and oil quenched; they were then tempered at $453 \mathrm{~K}\left(180^{\circ} \mathrm{C}\right)$ for 1 hour and air cooled to give the microstructure of tempered martensite. The average grain size of original austenite is $10 \mu \mathrm{m}$ measured from 167 grains on 11 observation fields. The average ultimate tensile strength is $2372 \mathrm{MPa}$ from the tensile tests on four specimens with the same heattreatment procedure.

The raw specimens of material $\mathrm{C}$ were heated at $1118 \mathrm{~K}\left(845^{\circ} \mathrm{C}\right)$ for 2 hours and oil quenched; they were then tempered at $473 \mathrm{~K}\left(200{ }^{\circ} \mathrm{C}\right)$ for 1 hour and air cooled. Such heat-treated specimens are of the microstructure with tempered martensite. The average size of original austenite grains is $11.2 \mu \mathrm{m}$ measured from 200 grains of intergranular morphology on SEM photos taken of fracture surfaces. The average ultimate tensile strength is $1768 \mathrm{MPa}$ from the tensile tests on four specimens with the same heat-treatment procedure.

The surfaces of diameter reduced part for the heattreated specimens were ground and polished to a smooth finish in order to eliminate the machining scratches. Thus, the specimens were ready for fatigue testing.

Fatigue tests were performed by using a rotary bending machine at laboratory air environment of room temperature, for which the rotating speed of the axis was

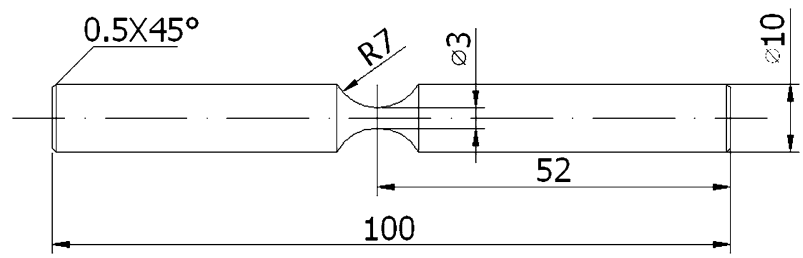

Fig. 1-Schematic drawing of hour-glass-shape specimen for rotary bending fatigue test (dimensions in millimeters).
$3150 \mathrm{rpm}$, i.e., the frequency being $52.5 \mathrm{~Hz}$. The machine contains two pairs of rotating axes, each with two ends for clamping specimens, such that it is capable of allowing four specimens to be tested simultaneously. A weight was independently loaded to the end of each specimen through a fixture as a cantilever type loading. The loaded weight was given by the conversion of required applied stress with a simple relation, and the stress ratio was -1 for this type of cyclic loading.

Figure 2 shows the experimental results of the S-N relation for the two test materials. For material $G$ (GCr15), the failure cycles ranged from $4 \times 10^{4}$ to $4 \times 10^{8}$ (Figure 2(a)), and for material C $(40 \mathrm{Cr}$ ), the failure cycles ranged from $8 \times 10^{4}$ to $4 \times 10^{8}$ (Figure 2(b)). The cycling ranges for both cases passed through the high-cycle fatigue regime and entered the VHCF regime. It is obvious that fatigue failure for both test materials happened at the loading cycles beyond $10^{7}$ even over $10^{8}$, suggesting that the traditional fatigue

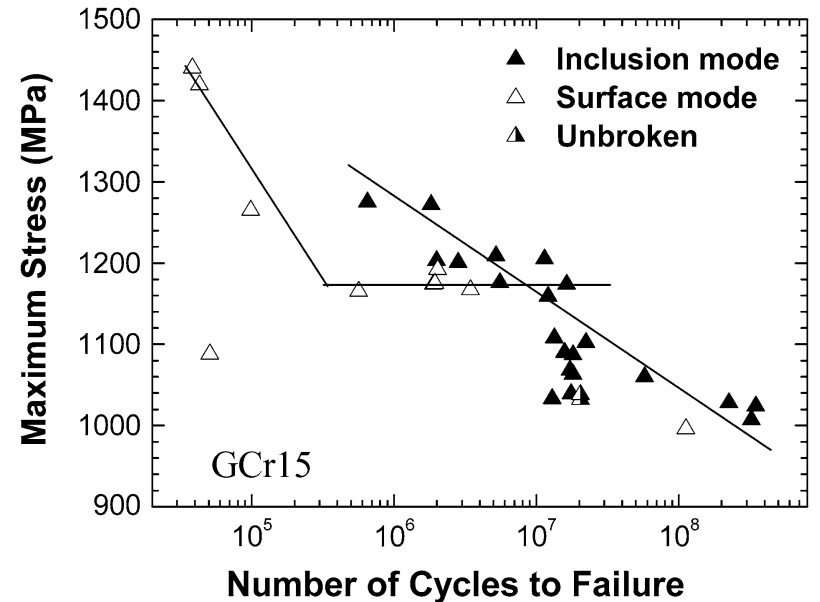

(a)

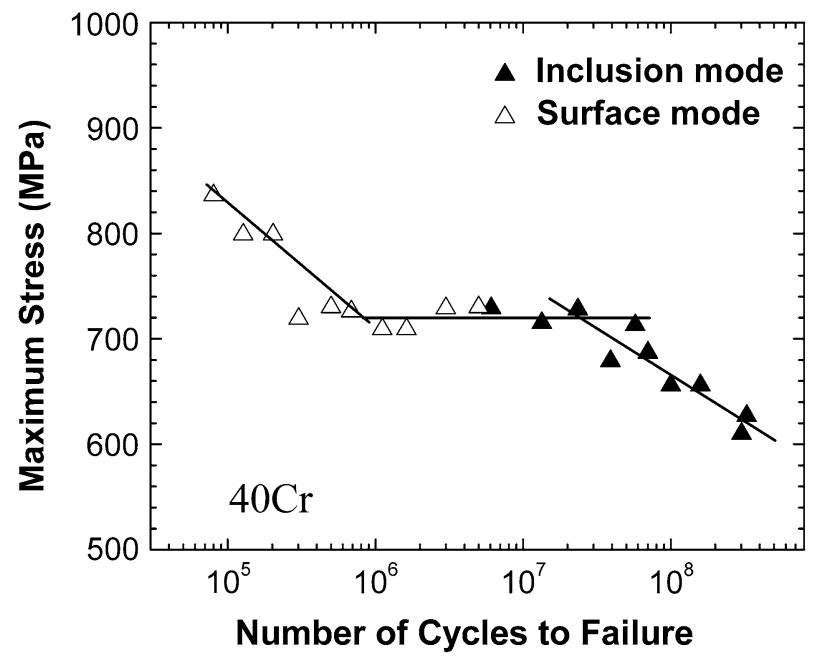

(b)

Fig. 2-Results of rotary bending tests showing fatigue strength $v s$ number of cycles to failure for two test materials and the symbol styles indicating the mode of fatigue crack initiation: $(a)$ results of material $\mathrm{G}(\mathrm{GCr} 15)$ and $(b)$ results of material $\mathrm{C}(40 \mathrm{Cr})$. 
limit no longer existed. The shape of the $\mathrm{S}-\mathrm{N}$ curves shown in Figure 2 presents a stepwise tendency, and this is more evident for material $\mathrm{C}$ (Figure 2(b)). The stepwise shape of the $\mathrm{S}-\mathrm{N}$ curve is one of the VHCF specific characteristics for metallic materials. ${ }^{[1,12,16,18]}$ The symbol styles in Figure 2 also indicate the mode of fatigue crack initiation, which will be described in the next part of this article.

\section{FRACTOGRAPHY}

Fracture surfaces of broken specimens were examined by scanning electron microscopy (SEM) and optical microscopy (OM). During the examination, special attention was given to the crack initiation region.

Figures 3(a) through (c) are the fracture surface of VHCF for a specimen of material $\mathrm{G}$, showing the region of crack initiation. The photograph of low magnification (Figure 3(a)) indicates three regions of different gray levels and the location of crack origination on the fracture surface. Region A is the crack initiation and early growth zone, which is responsible for a substantially large part of fatigue life. Region $\mathrm{B}$ is the crack fast growth zone, and region $\mathrm{C}$ is the final fracture zone. The enlargement of region A (Figure 3(b)) shows the typical patterns of optical-dark-area (also named fine-granular- area (FGA)) and fish-eye, with the latter being tangent to the specimen surface. The diameter of the fish-eye is about $200 \mu \mathrm{m}$ and that of the inside optical-dark-area is about $50 \mu \mathrm{m}$. Further enlargement of the crack initiation region (Figure 3(c)) shows the embedded inclusion of about $10 \mu \mathrm{m}$ in diameter, which is the crack origin and debonds from its embraced matrix.

Figures 4(a) through (c) show the fractography of a specimen of material $\mathrm{C}$ after $\mathrm{VHCF}$ failure. The low magnification image (Figure 4(a)) shows the entire fracture surface, where the left part is the crack origination region. The enlargement of the crack origination region (Figure 4(b)) shows the subsurface crack initiation with a fish-eye pattern. The further enlargement (Figure 4(c)) shows the crack origin due to an inclusion with clear evidence of interface debonding of the inclusion from the surrounding matrix.

Figures 3 and 4, which are typical examples of VHCF fractography for materials $\mathrm{G}$ and $\mathrm{C}$, respectively, indicate that for the low alloy steels tested, subsurface crack initiation is preferable to surface initiation at the VHCF regime. The interface debonding of the related subsurface inclusion from its surrounded matrix leads to VHCF crack initiation. When the crack initiation zone (fish-eye) extends and approaches the specimen surface, the fatigue crack enters into the early steady growth period.

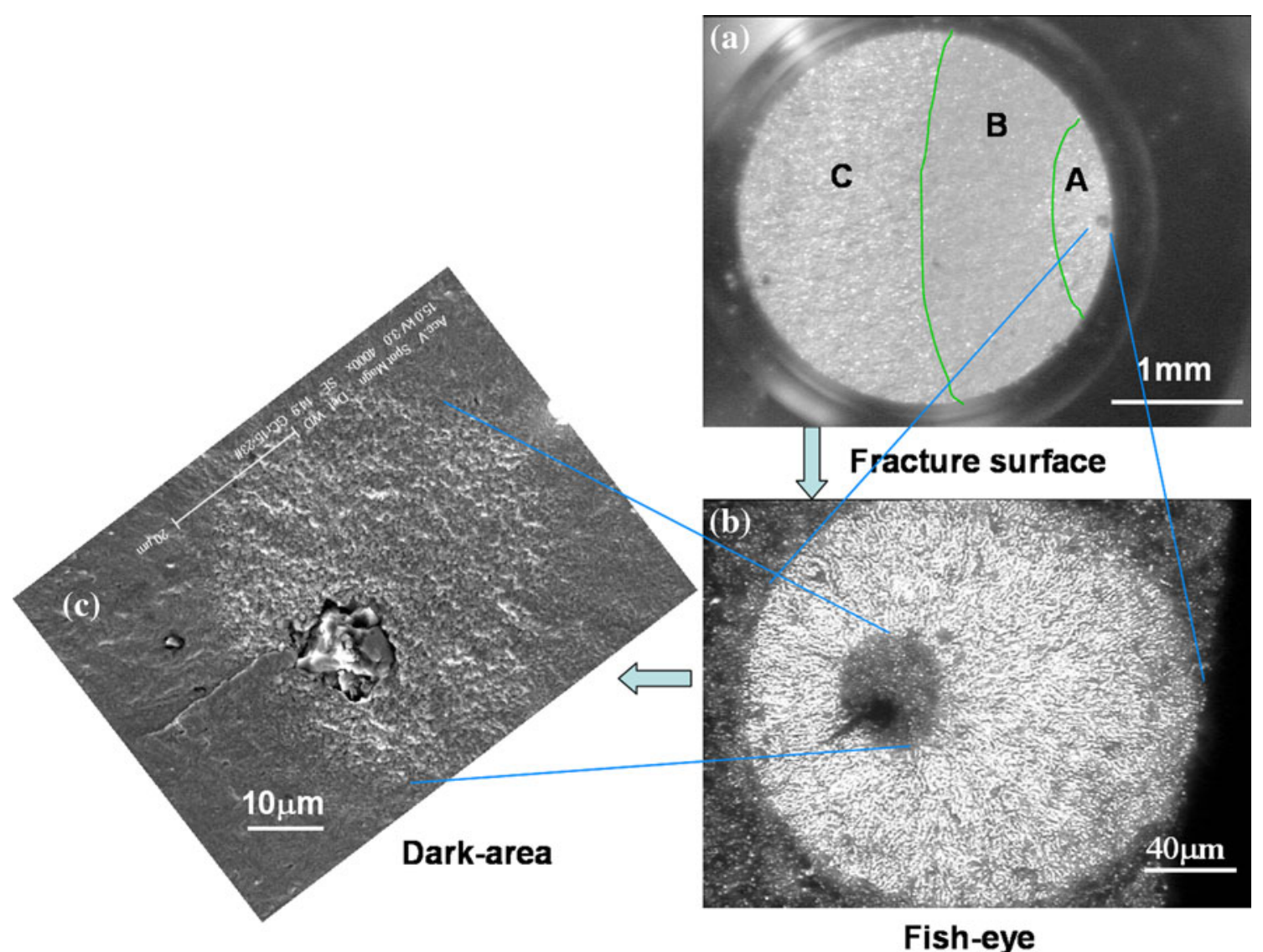

Fig. 3-Fracture surface of specimen G1 at VHCF regime with $\sigma_{\max }=1024 \mathrm{MPa}$ and $N_{f}=3.5 \times 10^{8}$, showing fatigue crack originated from an inclusion at the subsurface: (a) OM photo of whole fracture surface, (b) OM photo of fish-eye pattern, and (c) SEM photo of dark-area morphology. 

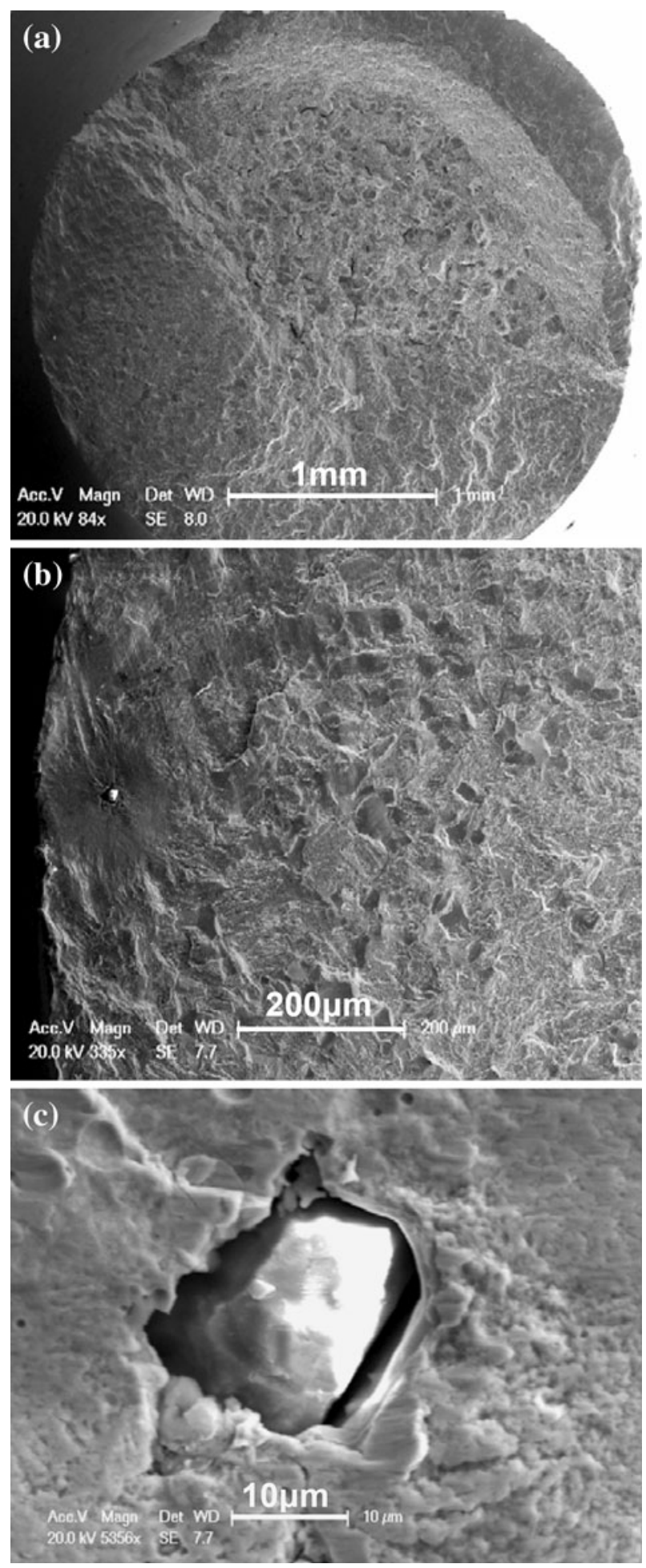

Fig. 4 -SEM photos showing fractography of specimen $\mathrm{Cl}$ after VHCF failure with $\sigma_{\max }=610 \mathrm{MPa}$ and $N_{f}=3.27 \times 10^{8}:(a)$ whole fracture surface with left part being the crack initiation region, $(b)$ enlargement of the crack initiation region with a fish-eye underneath the surface, and $(c)$ enlargement of the inclusion embedded in the fish-eye with clear evidence of interface debonding.

In addition to the subsurface origination of fatigue cracks at the VHCF regime, fatigue cracks may normally initiate from the surface at low-cycle and highcycle regimes, as also indicated by the symbol styles in

\section{surface crack
origination}
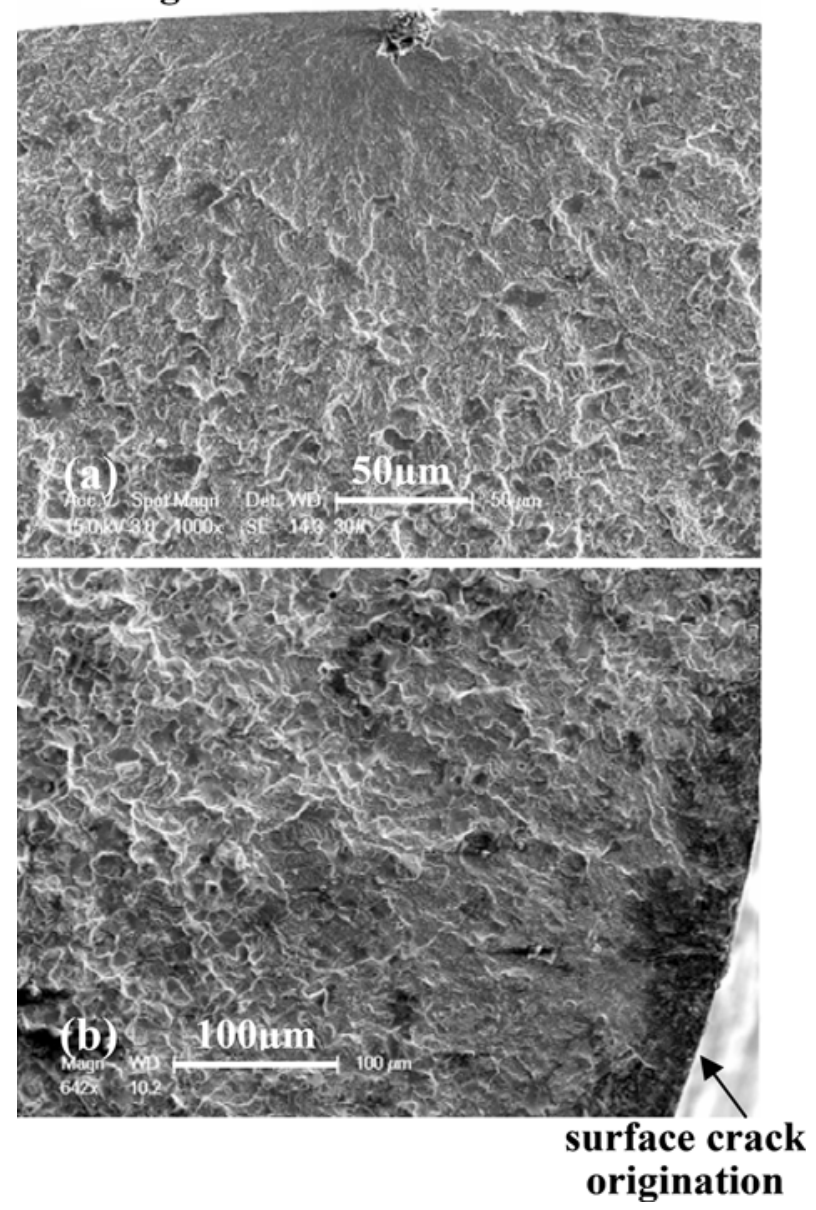

Fig. 5-Fractography of fatigue crack initiation at the specimen surface: $(a)$ specimen $\mathrm{G} 2$ with $\sigma_{\max }=1419 \mathrm{MPa}$ and $N_{f}=4.3 \times 10^{4}$ and $(b)$ specimen $\mathrm{C} 2$ with $\sigma_{\max }=720 \mathrm{MPa}$ and $N_{f}=1.1 \times 10^{6}$.

Figure 2. For material G, fatigue cracks almost initiate at the specimen surface for failure cycles below $10^{6}$, and both surface and subsurface initiation prevail for failure cycles between $10^{6}$ and $10^{7}$. For material $\mathrm{C}$, the usual surface crack origination occurs when the failure cycles below $5 \times 10^{6}$. Figures $5(\mathrm{a})$ and (b) are SEM photos showing fatigue crack initiation at the specimen surface for specimens $\mathrm{G} 2$ and $\mathrm{C} 2$. The former is due to an inclusion at the surface (Figure 5(a)), and the latter is without the participation of an inclusion (Figure 5(b)).

Figures 6(a) through (c) are the measurements of fisheyes and embedded inclusions from the crack initiation region of 10 specimens of material $\mathrm{C}$, for which the values of $2 a$ and $2 b$ of fish-eye, the depth of inclusion, and the diameter of inclusion were measured from the SEM photos taken of the fracture surfaces. It is seen that the ratio of $2 a_{i}$ to $2 b_{i}$ of fish-eye is between 0.85 and 1.15 (Figure 6(a)), indicating that the dimension of fisheye in the direction perpendicular to the specimen surface is equal, on average, to the length parallel to the specimen surface; i.e., the shape of fish-eye is almost equiaxed. Figure 6(b) shows that the distance (i.e., the 
depth) of the embedded inclusion away from the specimen surface increases with the related fatigue failure cycles, which indicates that if the location of an inclusion is with large depth from the surface, the crack initiation zone, i.e., the size of the fish-eye, will be relatively large; therefore, a large value of fatigue cycles will be expected for the initiation period. Figure 6(c) shows the diameter of the inclusion as the crack origin decreases with the related fatigue failure cycles, indicating that large inclusions may cause an early initiation of fatigue crack and lead to a shorter fatigue life, whereas relatively small inclusions may upgrade the fatigue resistance of the material.

The dimension measurements of fish-eyes and embedded inclusions for material $G$ show that the size of fisheye is irrelevant to fatigue failure cycles (Figure 7(a)) and that the fish-eye radius is linearly proportional to the embedded inclusion depth underneath the specimen surface (Figure 7(b)) with a fit of $y=0.74 x$. On one hand, the size of a fish-eye is dependent of the location of the related inclusion that causes the crack initiation, and the further the inclusion away from the surface, the larger the fish-eye will be. On the other hand, the initial growth of fish-eye crack is somewhat faster outward to the specimen surface than inward to the specimen center.

As mentioned in the interpretation of Figure 3, region $\mathrm{A}$ is responsible for a substantially large part of fatigue life. In a parallel article, ${ }^{[21]}$ we further investigated the characteristics and the threshold mechanical value for the fish-eye and FGA in region $\mathrm{A}$. In addition, the investigation of the fish-eye and FGA for VHCF of high strength steels also may be referred to recent publications. ${ }^{[18,22-24]}$

In order to further investigate the crack propagation process, we designed a kind of v-notch specimen testing, in which a circumferential v-notch was introduced at the reduced section of the rotary bending specimen (Figure 1). Fatigue cycling of a group of specimens was interrupted for every specimen at a preset loading cycle, and the specimen was broken at low temperature in order to reveal the fatigue cracking damage evolution process. The experimental details and results were reported elsewhere. ${ }^{[25,26]}$

\section{CRACK INITIATION MECHANISM}

For the two test materials, all the fatigue fracture surfaces of either surface crack initiation or subsurface crack initiation modes present the morphology of three regions, as shown in Figure 3(a). Regarding the inner boundary as a crack tip for regions $\mathrm{A}$ and $\mathrm{B}$ at the fracture surface, i.e., the crack length $a$ is taken as A for region A or as B for region B (Figure 8(a)), one may

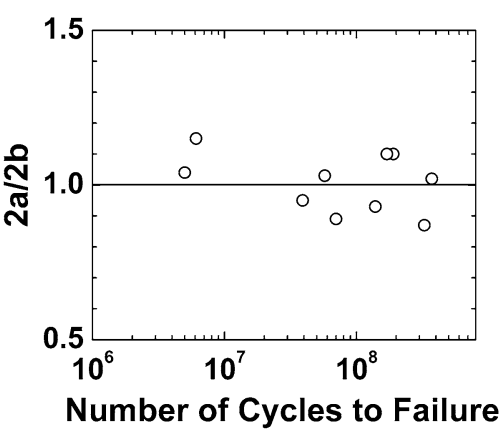

(a)

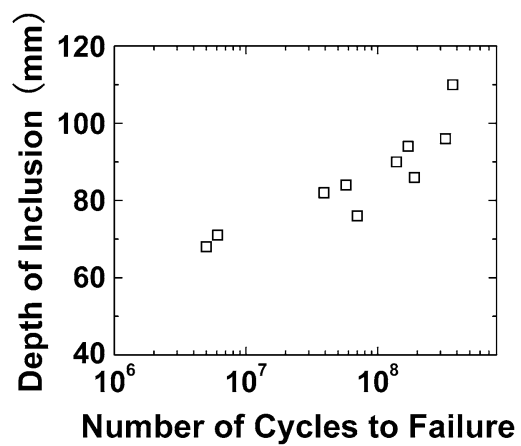

(b)

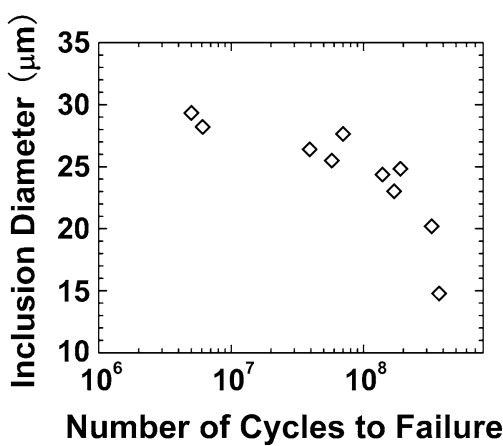

(c)

Fig. 6-Measurements of dimensions for fish-eyes and imbedded inclusions for specimens of material C: $(a) 2 a / 2 b$ of fish-eye $v s \quad N_{f},(b)$ depth of inclusion $v s N_{f}$, and (c) inclusion diameter $v s N_{f}$.

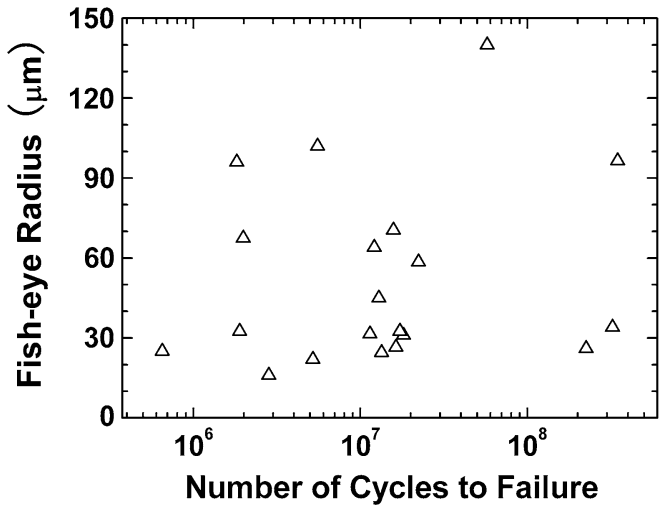

(a)

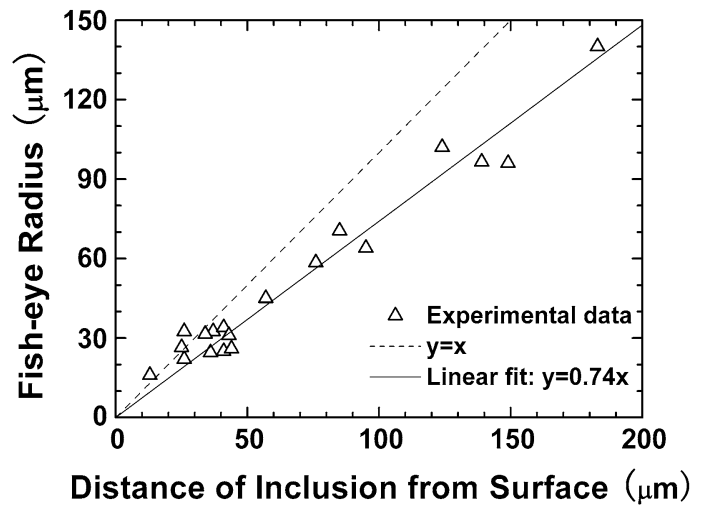

(b)

Fig. 7-Measurements of dimensions for fish-eyes and embedded inclusions for specimens of material G. 


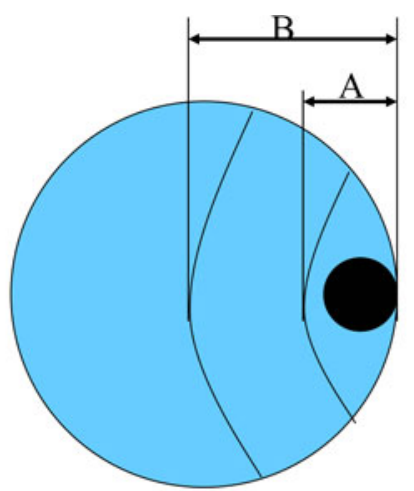

(a)

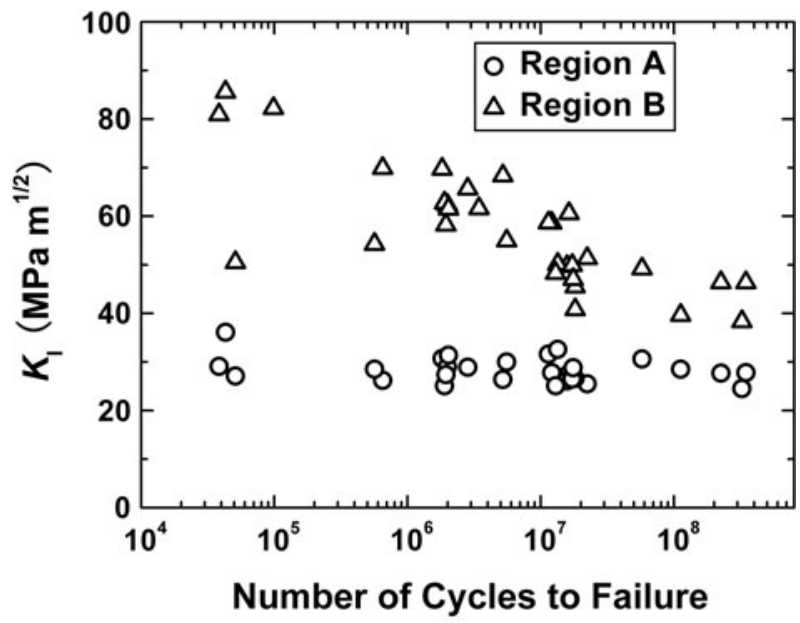

(b)

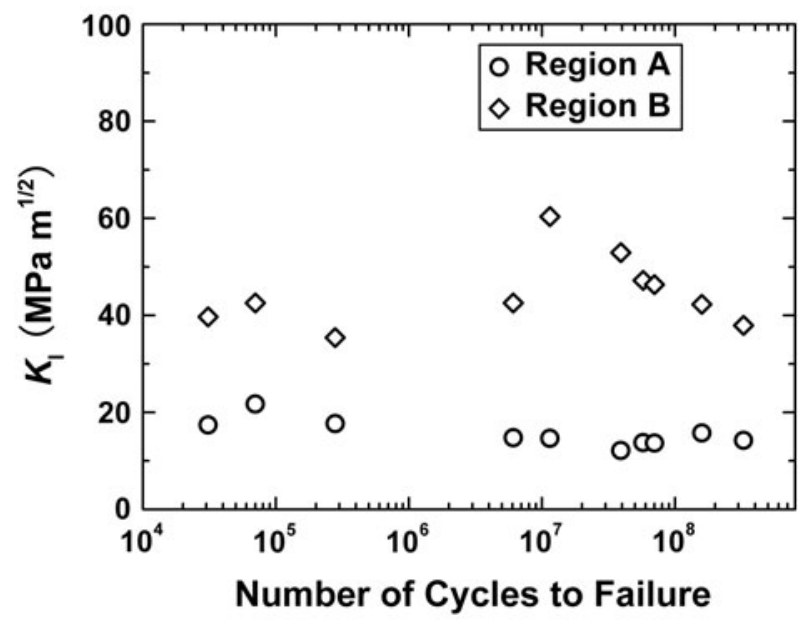

(c)

Fig. 8- $K_{I}$ values $v s$ fatigue failure cycles for regions $\mathrm{A}$ and $\mathrm{B}$ of fracture surface: (a) schematic of regions A and B on the fracture surface referred to Fig. 3(a), (b) results of material G (GCr15), and (c) results of material $\mathrm{C}(40 \mathrm{Cr})$.

calculate the stress intensity factor $K_{I}$ with the following formula:

$$
K_{I}=F \sigma_{a} \sqrt{\pi a}
$$

In the calculation, region $\mathrm{A}$ is regarded as elliptical shape and region $\mathrm{B}$ is regarded as circular shape. Figure $8(\mathrm{~b})$ is the result of $K_{I} v s$ fatigue failure cycles for material $\mathrm{G}$, and Figure 8(c) is that for material C. It is seen from Figure 8 that the values of $K_{I}$ almost remain constant from low cycle to $\mathrm{VHCF}$ regime for region $\mathrm{A}$ for both materials. The average value of $K_{I}$ for region $\mathrm{A}$ for material $\mathrm{G}$ is $28 \mathrm{MPa} \mathrm{m}^{1 / 2}$, and that for material $\mathrm{C}$ is $16 \mathrm{MPa} \mathrm{m}^{1 / 2}$. It is also seen from Figure 8 that the values of $K_{I}$ for region $\mathrm{B}$ are largely scattered, with the range between 38 and $86 \mathrm{MPa} \mathrm{m}^{1 / 2}$ for material $\mathrm{G}$ and between 35 and $60 \mathrm{MPa} \mathrm{m}{ }^{1 / 2}$ for material C. In addition, we use the same method to obtain the $K_{I}$ values for fisheye regions. The average $K_{I}$ value of fish-eye regions for material $\mathrm{G}$ (20 specimens) is $9.2 \mathrm{MPa} \mathrm{m}^{1 / 2}$ and that for material C (10 specimens) is $10.1 \mathrm{MPa} \mathrm{m}^{1 / 2}$. Such values for the two materials are close to the corresponding $\Delta K_{t h}$ values, ${ }^{[10]}$ implying that fish-eye region is the fatigue crack initiation zone. Thereafter, fatigue crack enters the steady growth stage (region A), and region B is probably the crack fast growth zone. The $K_{I}$ value of region B of the fracture surface, although with large scattering, is relevant to the corresponding fracture toughness.

In order to interpret the competition mechanism of fatigue crack initiation either at the surface or at the subsurface, we propose a new parameter $D^{*}$ for this regard:

$$
D^{*}=\frac{N_{i}}{N_{s}}
$$

In fact, $D^{*}$ is the ratio of two general time variables, which is called the Deborah factor in reference to the Deborah number proposed in Reference 27. When $N_{s}<N_{i}$, i.e., $D^{*}>1$, cracks originate at the surface. On the contrary, when $N_{s}>N_{i}$, i.e., $D^{*}<1$, cracks initiate at the subsurface (interior).

Note that crack initiation related to inclusions could be of different cases. One is the weak cohesive state between the inclusion and matrix (case A). Under cyclic loading, a crack will easily form due to the interface debonding and grow into the matrix. The other is the strong cohesive state between the inclusion and matrix (case B). Crack initiation is due to the localization of nonuniform deformation at the local region of the interface between the inclusion and matrix. Referring to the derivation of $D^{*}$ in the Appendix with Eqs. [A18] and [A25], we may write the basic expressions of $D^{*}$ for cases $\mathrm{A}$ and $\mathrm{B}$, respectively.

For case A,

$$
D^{*}=\frac{N_{i}}{N_{s}}=\frac{1.25 k_{w}(\varphi-1)^{2}}{\Delta \tilde{U} \psi^{2}}
$$

For case B,

$$
D^{*}=\frac{N_{i}}{N_{s}}=\frac{2.5 k_{w}\left(\varphi^{2}-1\right)^{2}}{\Delta \tilde{U}_{1}}
$$

In this calculation, $k_{w}$ is taken as unity. Thus, we may calculate the values of $D^{*}$ as a function of $\varphi$ and $\psi$, and 


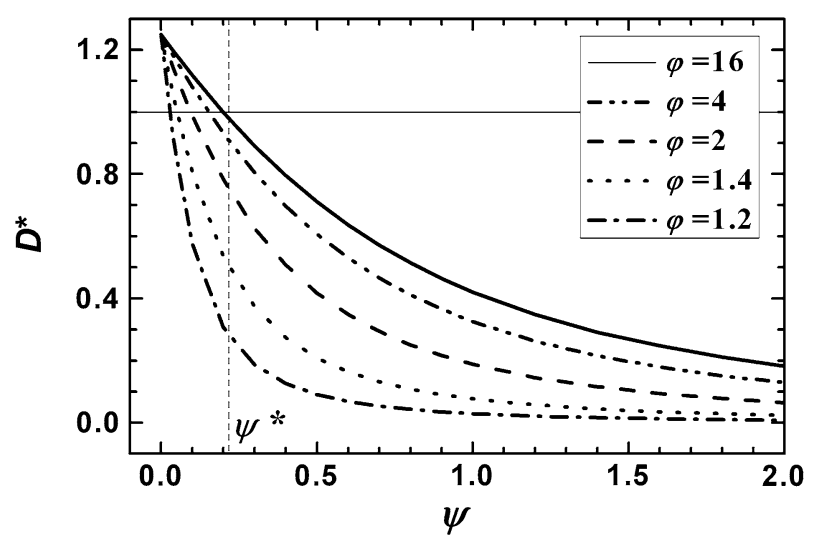

(a)

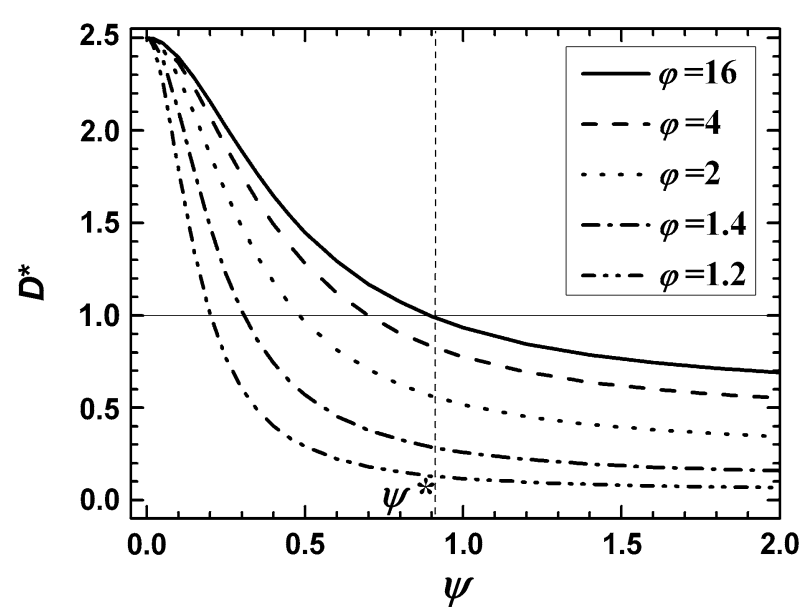

(b)

Fig. 9- Calculated values of $D^{*}$ as a function of $\varphi$ and $\psi:(a)$ results of case A and $(b)$ results of case B.

the results are shown in Figure 9. For the sake of clear description in the following discussion, recall the definitions of $\varphi$ and $\psi . \varphi=0.5 \Delta \sigma / k$ represents the ratio of applied stress amplitude $\Delta \sigma$ to dislocation resistance $k$, with the value of $\varphi$ taken as 1.2, 1.4, 2.0, 4.0, and 16 in the calculation. $\psi=r / l$ represents the ratio of the inclusion radius $r$ to grain radius $l$, with the range of $\psi$ taken from 0.0 to 2.0 .

There is a horizontal line of $D^{*}=1$ in Figure 9. For the zone of $D^{*}>1$, cracks tend to initiate at the surface, whereas for the zone of $D^{*}<1$, cracks tend to originate at the subsurface. By comparison of Figures 9(a) and (b), the zone of $D^{*}<1$ for case A is much larger than that for case $\mathrm{B}$, indicating that fatigue cracks more possibly initiate at the subsurface in the circumstance of the weak cohesive state between inclusion and matrix. This is consistent with the observations of interfacial debonding between the subsurface inclusion and surrounding matrix (Figures 3(c) and 4(c)).

For the sake of further discussion, we define $\psi^{*}$ as the $\psi$ value corresponding to the intersection point between the distribution curve of $\varphi=16$ and the line of $D^{*}=1$. Thus, for case $\mathrm{A}, \psi^{*}$ is about 0.2 , whereas for case $\mathrm{B}, \psi^{*}$ is about 0.9. For a given loading state ( $\varphi$ is constant), when $\psi<\psi^{*}$, i.e., small inclusion size $r$ or large grain size $l$, if $D^{*}>1$, crack initiation tends toward the surface. With the increase of $\psi$, i.e., the increase of inclusion size $r$ or the decrease of grain size $l$, the value of $D^{*}$ gradually decreases and leads to $D^{*}<1$; then fatigue crack initiation will shift from "at surface" to "at subsurface." On the other hand, when $\psi$ is given, the value of $D^{*}$ decreases with the decrease of $\varphi$ (decrease of loading level $\Delta \sigma$ or increase of dislocation resistance $k$, i.e., the strength of material). Thus, fatigue cracks tend to initiate at the subsurface. This may be interpreted as indicating that surface crack initiation occurs at shorter fatigue cycles under relatively higher loading levels and subsurface crack origination occurs at longer fatigue cycles under relatively lower loading levels.

In general, fatigue crack initiation tends toward the subsurface at the situation of relatively low cyclic loading level, high strength of material, large inclusion size, small grain size, and vice versa.

\section{CONCLUSIONS}

The following conclusions are drawn for the low alloy steels subjected to the rotary bending test at the cycling frequency of $52.5 \mathrm{~Hz}$ and at laboratory air environment.

1. VHCF failure occurred up to fatigue cycles beyond $10^{8}$ with the S-N curves of stepwise tendency.

2. Crack initiation of VHCF is at subsurface inclusion with fish-eye pattern. The fish-eye is of equiaxed shape and tends to tangent the specimen surface. The size of fish-eye becomes large with the increasing depth of related inclusion from the surface. The fish-eye crack grows faster outward to the specimen surface than inward.

3. The $K_{I}$ value of fish-eye crack is close to the value of corresponding $\Delta K_{t h}$. Also, there is an early crack steady growth zone with constant $K_{I}$ value between $\Delta K_{t h}$ and fracture toughness.

4. A Deborah factor is proposed to interpret the competition mechanism of crack initiation at the surface or subsurface. Fatigue crack initiation tends toward subsurface at the situation of relatively low cyclic loading level, high strength of material, large inclusion size, and small grain size.

\section{ACKNOWLEDGMENTS}

The project was supported by the National Natural Science Foundation of China (Grant Nos. 11172304 and 10721202) and the Knowledge Innovation Program of the Chinese Academy of Sciences (Grant No. KJCX2-YW-L07). 


\section{APPENDIX: DERIVATION OF $D$ *}

Case A

For the case of weak cohesive bonding between inclusion and matrix (case A), the following relations were proposed in Reference 28:

$$
\begin{gathered}
\Delta \gamma=\frac{1}{2 A}(\Delta \sigma-2 k) l^{2} \\
\Delta U_{0}=\frac{1}{2} \Delta \gamma(\Delta \sigma-2 k)
\end{gathered}
$$

In such a case, when fatigue crack initiates from an inclusion at the subsurface, the criterion is

$$
U_{i}=2 N_{i} \Delta U_{i}=8 l w_{i}
$$

where

$$
\Delta U_{i}=\frac{\Delta \sigma \Delta \gamma_{1}^{T}}{2}-k \Delta \gamma_{1}^{L}+\frac{r^{2} \Delta \sigma^{2}}{2 A}
$$

with

$$
\begin{gathered}
\Delta \gamma_{1}^{T}=\frac{\beta \Delta \sigma}{A}\left(2 c^{2}-r^{2}\right) \\
+\frac{2 k r}{\pi A}\left[3 \sqrt{c^{2}-r^{2}}-2 r I\right]+\frac{k r^{2}}{2 A} \\
\Delta \gamma_{1}^{L}=\frac{2 \beta \Delta \sigma}{\pi A}\left[c^{2} \cos ^{-1} \frac{r}{c}-d \sqrt{c^{2}-r^{2}}+\frac{\pi}{2}\left(c^{2}-r^{2}\right)\right] \\
+\frac{4 k r}{\pi^{2} A}\left[\sqrt{c^{2}-r^{2}}\left(\pi+\cos ^{-1} \frac{r}{c}\right)+2 r \ln \frac{r}{c}-\pi r I\right] \\
\beta=1-\frac{k}{\Delta \sigma}-\frac{2 k}{\pi \Delta \sigma} \cos ^{-1}\left(\frac{r}{c}\right)
\end{gathered}
$$

and

$$
I=\frac{1}{\pi r^{2}} \int_{r}^{c} \frac{t^{2}}{\sqrt{t^{2}-r^{2}}} \ln \left|\frac{t \sqrt{c^{2}-r^{2}}+r \sqrt{c^{2}-t^{2}}}{t \sqrt{c^{2}-r^{2}}-r \sqrt{c^{2}-t^{2}}}\right| d t
$$

Case B

For the case of strong cohesive state between the inclusion and matrix (case B), the following relations were also proposed in Reference 28:

$$
\begin{gathered}
\Delta \gamma=\frac{3}{2 A}(\Delta \sigma-2 k) l^{2} \\
\Delta U_{0}=\frac{C}{2} \Delta \gamma(\Delta \sigma-2 k)
\end{gathered}
$$

with

$$
C=\frac{1}{3}\left[1+2 \ln \left(\frac{2 R}{l}\right)\right]
$$

The criterion for crack initiation is

$$
U_{i}=2 N_{i} \Delta U_{i}=4 l w_{i}
$$

Referred to Reference 29, one has

$$
\begin{aligned}
\Delta U_{i}= & \frac{\Delta \sigma-2 k}{4 A}\left\{\beta_{0} \Delta \sigma l^{2}+2 \Delta \sigma r^{2}\left[1-\frac{r\left(3 l^{2}+2 r^{2}\right)}{2\left(l^{2}+r^{2}\right)^{3 / 2}}\right]\right\} \\
& +\frac{\beta_{0} \Delta \sigma^{2} r^{2}}{2 A}\left(1-\frac{r}{\sqrt{l^{2}-r^{2}}}\right) \\
& +\frac{\Delta \sigma^{2} r^{5}}{2 A} \frac{1}{\left(R+r^{2}\right)^{3 / 2}}\left(\frac{4 r^{4}+2 r^{2} l^{2}+l^{4}}{4 r^{3} \sqrt{l^{2}+r^{2}}}-1\right)[\mathrm{A} 12
\end{aligned}
$$

with

$$
\beta_{0}=1-\frac{2 k}{\Delta \sigma}+\frac{r^{3}}{\left(l^{2}+r^{2}\right)^{3 / 2}}
$$

\section{Crack Initiation at Surface}

For fatigue crack initiation at the surface, the situation of case A with Eqs. [A1] and [A2] is approximately referred. ${ }^{[28]}$ Considering the surface crack factor and half-cycling process, one has

$$
\Delta U_{s}=1.12^{2}\left(\frac{1}{2} \Delta U_{0}\right)=\frac{1.25}{2 A} l^{2}(\Delta \sigma-2 k)^{2}
$$

Generally,

$$
U_{s}=2 N_{s} \Delta U_{s}=4 l w_{s}
$$

Thus,

$$
N_{s}=\frac{4 A w_{s}}{1.25 l(\Delta \sigma-2 k)^{2}}
$$

\section{Expressions of $D^{*}$}

The basic definition of $D^{*}$ is the ratio of $N_{i}$ to $N_{s}$. Thus, from Eqs. [A3] and [A15], one may write the following formula for case A:

$$
D^{*}=\frac{N_{i}}{N_{s}}=2 k_{w} \frac{\Delta U_{s}}{\Delta U_{i}}
$$

The further derivation may give the expression of $D^{*}$ for case A:

$$
D^{*}=\frac{1.25 k_{\mathrm{w}}(\varphi-1)^{2}}{\Delta \tilde{U} \psi^{2}}
$$

Here, the dimensionless unit increment of energy $\Delta \tilde{U}$ is

$$
\Delta \tilde{U}=\frac{\varphi \Delta \tilde{\gamma}_{1}^{T}-\Delta \tilde{\gamma}_{1}^{L}+\varphi^{2}}{2}
$$

with

$$
\Delta \tilde{\gamma}_{1}^{T}=\beta \varphi\left(2 \tilde{c}^{2}-1\right)+\frac{1}{\pi}\left(3 \sqrt{\tilde{c}^{2}-1}-2 \tilde{I}\right)-\frac{1}{4}
$$




$$
\begin{aligned}
\Delta \tilde{\gamma}_{1}^{L}= & \frac{2 \beta \varphi}{\pi}\left[\tilde{c}^{2} \cos ^{-1}\left(\frac{1}{\tilde{c}}\right)-\sqrt{\tilde{c}^{2}-1}+\frac{\pi}{2}\left(\tilde{c}^{2}-1\right)\right] \\
& +\frac{2}{\pi^{2}}\left\{\sqrt{\tilde{c}^{2}-1}\left[\pi+\cos ^{-1}\left(\frac{1}{\tilde{c}}\right)\right]+2 \ln \left(\frac{1}{\tilde{c}}\right)-\pi \tilde{I}\right\}
\end{aligned}
$$

$$
\begin{gathered}
\beta=1-\frac{1}{2 \varphi}-\frac{1}{\pi \varphi} \cos ^{-1}\left(\frac{1}{\tilde{c}}\right) \\
\tilde{c}=\frac{c}{r}=\frac{\psi}{2(\psi+2)}\left[1+\left(1+\frac{2}{\psi}\right)^{2}\right]
\end{gathered}
$$

and

$$
\tilde{I}=\frac{1}{\pi} \int_{1}^{\tilde{c}} \frac{t^{2}}{\sqrt{t^{2}-1}} \ln \left|\frac{t \sqrt{\tilde{c}^{2}-1}+\sqrt{\tilde{c}^{2}-t^{2}}}{t \sqrt{\tilde{c}^{2}-1}-\sqrt{\tilde{c}^{2}-t^{2}}}\right| d t
$$

Similarly, one may write the following expression of $D^{*}$ for case B:

$$
D^{*}=\frac{N_{i}}{N_{s}}=k_{w} \frac{\Delta U_{s}}{\Delta U_{i}}=\frac{2.5 k_{w}\left(\varphi^{2}-1\right)^{2}}{\Delta \tilde{U}_{1}}
$$

Here,

$$
\begin{aligned}
\Delta \tilde{U}_{1}= & (\varphi-1)\left\{\varphi \beta_{0}+2 \varphi \psi^{2}\left[1-\frac{\psi\left(2 \psi^{2}+3\right)}{2\left(\psi^{2}+1\right)^{3 / 2}}\right]\right\} \\
& +2 \varphi^{2} \psi^{2} \beta_{0}\left(1-\frac{\psi}{\sqrt{\psi^{2}+1}}\right) \\
& +\frac{2 \varphi^{2} \psi^{2}}{\left(1+\frac{1}{\psi^{2}}\right)^{3 / 2}}\left(\frac{4 \psi^{4}+2 \psi^{2}+1}{4 \psi^{3} \sqrt{\psi^{2}+1}}-1\right)
\end{aligned}
$$

and

$$
\beta_{0}=1-\frac{1}{\varphi}+\left(1+\frac{1}{\psi^{2}}\right)^{-3 / 2}
$$

In short, Eqs. [A18] and [A25] are the basic expressions of $D^{*}$ for cases $\mathrm{A}$ and $\mathrm{B}$, respectively, which are used for the simulation and therefore for the discussion of the competition mechanism for fatigue crack initiation at surface or at subsurface.

\section{TABLE OF SYMBOLS}

a crack length

$2 a_{i} \quad$ fish-eye dimension in direction perpendicular to specimen surface

$A \quad \mu /[(2 \pi(1-v)]$

$2 b_{i} \quad$ fish-eye dimension in direction parallel to specimen surface
$D^{*} \quad$ Deborah factor

$F \quad$ correction factor of crack shape

$K \quad$ resistance of dislocation movement

$k_{w} \quad w_{\mathrm{i}} / w_{\mathrm{s}}$

$K_{I} \quad$ stress intensity factor

$\Delta K_{t h}$

$L$

$N_{f} \quad$ fatigue failure cycles

$N_{i} \quad$ fatigue cycles required for crack initiation at subsurface

$N_{s} \quad$ fatigue cycles required for crack initiation at surface

$r \quad$ inclusion radius

$R \quad$ radius of dislocation stress field

$U_{i} \quad$ total energy related to dislocation pipe-ups for subsurface crack initiation

$U_{s} \quad$ total energy related to dislocation pipe-ups for surface crack initiation

$\Delta U_{0} \quad$ unit increment of energy

$\Delta \tilde{U}, \quad \Delta \tilde{U}_{1}$ dimensionless unit increment of energy

$\Delta U_{i} \quad$ unit increment of energy for subsurface crack initiation

$\Delta U_{s} \quad$ unit increment of energy for surface crack initiation

$w_{i} \quad$ surface energy related to subsurface crack initiation

$w_{s} \quad$ surface energy related to surface crack initiation

$\Delta \gamma \quad$ increment of plastic deformation

$\mu \quad$ shear modulus

$v \quad$ Poison's ratio

$\sigma_{a} \quad$ applied stress

$\sigma_{\max } \quad$ maximum applied stress

$\Delta \sigma \quad$ stress amplitude

$\Phi \quad 0.5 \Delta \sigma / k$

$\psi \quad r / l$

\section{REFERENCES}

1. A. Wöhler: Engineering, 1867, vol. 2, pp. 160-61.

2. Annual Book of ASTM Standards, E468-90 (2004), ASTM, Philadelphia, PA, 2006, Sect. 3, vol. 03.01, pp. 556-61.

3. M. Kikukawa, K. Ohji, and K. Ogura: J. Basic Eng., Trans. ASME D, 1965, vol. 87D, pp. 857-64.

4. T. Naito, H. Ueda, and M. Kikuchi: J. Soc. Mater. Sci. Jpn., 1983, vol. 32 , pp. $1162-66$.

5. T. Naito, H. Ueda, and M. Kikuchi: Metall. Trans. A, 1984, vol. 15A, pp. 1431-36.

6. S.E. Stanzl, E.K. Tschegg, and H. Mayer: Int. J. Fatigue, 1986, vol. 8, pp. 195-200.

7. P. Lukáš and L. Kunz: Fatigue Fract. Eng. Mater. Struct., 2002, vol. 25 , pp. $747-53$

8. Y. Murakami, N.N. Yokoyama, and J. Nagata: Fatigue Fract. Eng. Mater. Struct., 2002, vol. 25, pp. 735-46.

9. C. Bathias and P.C. Paris: Gigacycle Fatigue in Mechanical Practice, Marcel Dekker, New York, NY, 2005.

10. H. Emura and K. Asami: Trans. JSME, Part A, 1989, vol. 55, pp. $45-50$

11. T. Sakai, Y. Sato, and N. Oguma: Fatigue Fract. Eng. Mater. Struct., 2002, vol. 25, pp. 765-73.

12. K. Shiozawa, L. Lu, and S. Ishihara: Fatigue Fract. Eng. Mater. Struct., 2001, vol. 24, pp. 781-90.

13. Y. Ochi, T. Matsumura, K. Masaki, and S. Yoshida: Fatigue Fract. Eng. Mater. Struct., 2002, vol. 25, pp. 823-30.

14. S. Nishijima and K. Kanazawa: Fatigue Fract. Eng. Mater. Struct., 1999, vol. 22, pp. 601-07. 
15. C. Bathias: Fatigue Fract. Eng. Mater. Struct., 1999, vol. 22, pp. 559-65.

16. Q.Y. Wang, J.Y. Berard, S. Rathery, and C. Bathias: Fatigue Fract. Eng. Mater. Struct., 1999, vol. 22, pp. 673-77.

17. M.D. Chapetti, T. Tagawa, and T. Miyata: Mater. Sci. Eng. A, 2003, vol. 356, pp. 236-44.

18. Y. Hong, A. Zhao, and G. Qian: Acta Metall. Sinica, 2009, vol. 45, pp. $769-80$.

19. G. Qian, C. Zhou, and Y. Hong: Acta Mater., 2011, vol. 59, pp. 1321-27.

20. E. Takeuchi, Y. Furuya, N. Nagashima, and S. Matsuoka: Fatigue Fract. Eng. Mater. Struct., 2008, vol. 31, pp. 599-605.

21. C. Sun, A. Zhao, and Y. Hong: Struct. Longevity, 2011, vol. 045, pp. $1-12$.
22. T. Sakai: J. Solid Mech. Mater. Eng., 2009, vol. 3, pp. 425-39.

23. T. Sakai, Y. Sato, Y. Nagano, M. Takeda, and N. Oguma: Int. J. Fatigue, 2006, vol. 28, pp. 1547-54.

24. K. Shiozawa, Y. Morii, S. Nishino, and L. Lu: Int. J. Fatigue, 2006, vol. 28, pp. 1521-32.

25. G. Qian and Y. Hong: Acta Metall. Sinica, 2009, vol. 45, pp. 135663.

26. G. Qian, Y. Hong, and C. Zhou: Eng. Failure Analysis, 2010, vol. 17, pp. 1517-25.

27. Y.L. Bai, M.F. Xia, H.Y. Wang, and F.J. Ke: China Particuology, 2003, vol. 1, pp. 7-12.

28. T. Tanaka and T. Mura: J. Appl. Mech., Trans. ASME, 1981, vol. 48, pp. 97-103.

29. T. Tanaka and T. Mura: Metall. Trans. A, 1982, vol. 13A, pp. 117-23. 